\title{
A Review Article on Various Phytochemicals and Different Medicinal Activities of Haritaki.
}

\author{
Mitun Saha ${ }^{1 *}$, Mr. Bhupendra Kumar ${ }^{2}$, Dr. Amandeep Singh ${ }^{3}$ \\ $1 *$ Research Scholar, ${ }^{2}$ Assistant Professor, ${ }^{3}$ Principal, \\ 1, 2, 3 Dev Bhoomi Institute of Pharmacy and Research, Dehradun, Uttarakhand, India, Pin-248007
}

\begin{abstract}
Medicinal plant and plant products play very important role within the human culture to fight against ailments from the beginning of development [1].The application of herbal medicine in prevention and curing of ailments practiced from many years and also now in present time the Ayurveda medical system is reached everywhere in the globe, and it's well accepting by the people [2]. The home grown medication Haritaki (Terminalia Chebula Retz.) has a place with Combretaceae family and Used from crude time for restorative purposes [3]. Medicinal plant Haritaki is known as ' medicine king ' in country Tibet from numerous years back and It is constantly fixed it's place at the head of the record of 'Ayurveda Materia Medica' because of containing remarkable ability of recuperating with a huge range of biological activity [3, 4]. In Ayurveda Haritaki (Terminalia Chembula Retz.) is one of the most frequently used herbal drug, act as a foundation and additive natural remedy with mild Colonic Cleanse properties and It can be taken daily without except any ill effects and with great Benefits [5]. It keeps equilibrium in three doshas, Purification the channels along with nourishes all the dhatus of the body [6]. Ayurveda clinical Science Underline it's activity as Used in different sicknesses like Poor digestion (Agnimandya), Irritable bowel syndrome (Grahni), Constipation (Vibandha), Malaria (Vishamjwara), Gulma, Juandice (Kamla), Cough (Kasa), Skin disease (Kustha), stone (Ashmari) etc and also having the properties of Rejuvenating (Rasayan) and Age delaying (Vayasthapka) [6].In Contemporary, studies proved that, it displays a different number of pharmacological exercises like Antidiabetic activity,Radio-protective activity, Antiplasmodic activity, wound healling activity, Antiulcerogenic activity, Antioxidant and free radical scavenging activity, antibacterial, antiviral, antifungal, anticancerous, Antimutagenic, cardio-protective [7, 6, 5, $4,3,2,1]$.It is extravagant in different chemical compounds including tanning, phenolic Compound and flavonoids among them significant chemical compounds are chebulic acid, chebulinic acid, gallic acid, Corilagine, chebulagic acid, ellagic acid, triterpenoids and anthraquinones [3, 6]. Haritaki is an amazing drug which shows Preventive, promotive (of wellbeing) just as corrective in real life [6].In this review, we collected, highlights and summarized the all possible Updated information of phytochemicals, Pharmacological activity of haritaki, this gives an enormous information about the herb and their significant job in medicinal services and cleanliness $[3,8,9]$.
\end{abstract}

\begin{abstract}
Keywords:- Ayurveda; Haritak; Antidiabetic; RadioProtective; Cardio-Protective; Phytochemicals; Pharmacological Activity; Cleanliness.
\end{abstract}

\section{INTRODUCTION}

Life on Earth won't exist without plant. Human relies upon plants, as circuitous Source of vitality and asylum. Medicinal plant has been a Leading Origin of therapeutic agents from the very beginning of human Civilization $[4,10]$. It has been discovered that near about $80 \%$ of all settled common natural products obtained from plants (Philipson, 1990) [4] .The Renewal of Interest in normal natural medications began for the most part in most recent 10 years, due to broaden Spread belief that synthetic medicines are less beneficial for health than green medicine [4].In Present days, there is an expansion the quantity of therapeutic plant based enterprises due to the increment in light of a legitimate concern for utilization of restorative plants Entire the world which are developing at the pace of $7-15 \%$ every year [4] .World Health Organization (WHO) says, more than $80 \%$ of people groups of global populace in growing nations relies fundamentally upon plant base customary medication for their essential medicinal service's needs $[4,8,10,11]$. Traditional medical system around the globe uses natural cures are a significant asset for the revelation of present day drugs [11].While, looking through various restorative plants, Scientist discovers one of the most significant plant, that is haritak [11]. It is a most significant therapeutic plant in Indian customary medication, and it is most usable natural medication in Ayurveda [11]. The entire plant has high therapeutic Importance and generally utilized for the treatment of different sickness for Mankind's [10]. Always, it is listing top in Classics Ayurveda classics due to its extraordinary therapeutic benefits [2]. Haritaki comprises from dried pericarp of develop products of Terminalia chebula having a place with family-Combretaceae, which shows various therapeutic exercises in view of the nearness of different sorts of synthetic constituents in a huge number [11]. The fruits of the tree possesses different health benefits and it is an important household remedy used in various herbal formulation which is used in the treatment of most human diseases $[12,11]$. This plant Used in the treatment of Asthma, bore throat, regurgitating, hiccough, looseness of the bowels, diarrhea, draining heaps, ulcers, gout, heart and bladder sicknesses by some old stories people groups [10]. It is uses in significant formulations like Triphala, Abhyarihsta etc. which are generally utilized in India. Haritaki has been extensively utilized in Homeopathic and unani system of medication and has become a significant drug of present day 
medication [11]. Haritaki has been exhibited to have numerous pharmacological and restorative exercises, however not till now foundational data not refreshed on the remedial viability of Haritaki, has been successfully Reported $[1,11]$. This review features, Updated the knowledge specifically on numerous pharmacological exercises and medicinal properties of Haritaki [11].

1. TAXONOMICAL DESCRIPTION [4, 7, 8, 10, 11, 12].

* First Botanical name-Terminalia Chebula Retz.

* Botanical classification-

- Family: Combretaceae.

- Kingdom: Plantae.

- Subkingdom: Tracheobionta.

- Division: Mangnoliophyta.

- Class: Monocotyledons.

- Subclass-Epigynae.

- Order: Myrtales.

- Genus: Terminalia.

2. COMMON NAMES [3, 6, 7, 8, 11, 12, 13, 14]

Haritaki is distributed in a wide landscape of the earth and thus has got various names throughout the world.

Table Showing Vernacular Names Used In India [11, 13, $12,14]-$

\begin{tabular}{|c|c|}
\hline LANGUAGE & NAME \\
\hline Sanskrit & $\begin{array}{c}\text { Kayastha, Abhaya, shiva, Pathya, } \\
\text { Vijaya (Not Bhanga) }\end{array}$ \\
\hline Asamese & Shilikha. \\
\hline Bengali & Haritaki. \\
\hline English & Myrobalan \\
\hline Gujarati & Hirdo, Himaja, Pulo-harda \\
\hline Hindi & Harre, Harad, Harar \\
\hline Kannada & Alalekai. \\
\hline Kashmiri & Halela. \\
\hline Malayalam & Katukka. \\
\hline Marathi & Hirda, Haritaki, harda, Hireda. \\
\hline Punjabi & Halela, Harar. \\
\hline Tamil & $\begin{array}{l}\text { Ammai, Amutam, Aritaki, } \\
\text { Pethiyam,Varikkai. }\end{array}$ \\
\hline Telugu & Karakkaya,Karaka. \\
\hline
\end{tabular}

Table 1
Table Showing Vernacular Names Used By Different Countries-

\begin{tabular}{|c|c|}
\hline COUNTRY & NAME \\
\hline Filippines & Chebulic myrabolan. \\
\hline Franch & My robolan noir. \\
\hline Tibet & Zhang-Qin-Ge,Tlezi. \\
\hline China & Manja puteri. \\
\hline Malaysia & Myrobalane. \\
\hline Germany & Ahleelalj, Harar \\
\hline Arab & Samo thai. \\
\hline Thailand & Halela. \\
\hline Persian & Chieu lieu xanh. \\
\hline Vietnam & Haritaki, harad, harada. \\
\hline India & Sa mao tchet. \\
\hline Cambodia & \\
\hline
\end{tabular}

Table 2

\section{GEOGRAPHICAL DISTIBUTION}

It is a moderate to enormous estimated tree dispersed through tropical and subtropical Asia, including China and Tibet [8]. The favorable condition for growing of this plant is sunny, thickets, and moist forests with light rainfall $[4,12]$. This tree is found all through most of India, from Ravi eastwards to West Bengal and Assam, Indo-Burma district, climbing to an elevation of 1500 meters in the Himalayas $[11,12]$. It grows in deciduous backwoods of Himachal Pradesh, Tamilnadu, Kerala, Karnataka, Bihar, Orissa, Maharashtra, Uttar Pradesh, Madhya Pradesh and West Bengal $[12,15]$.

\section{PROPAGATION AND CULTIVATION $[4,10,11,12]$}

It develops on the assortment of soils however flourishes suitable in mud and sandy soil. The organic products mature from in the month November to March contingent on the area. Fallen natural products are gathered for the most part in first 50\% of January, seeds are dried and it can be preserved for more than one year. Seed germination is low because of hard spread and seed requires pre-planting treatment. The best germination is to happen when the seeds are chipped at their wide end without harming the incipient organism, and afterward absorbed water for $36 \mathrm{~h}$, before planting in nursery beds. Following 15 days of planting, germination starts and proceeds for 3-4 weeks. The tree can be effectively raised by stem cuttings or by transplanting the seedlings or by straightforwardly planting the seed. It is seen that transplanting of 1 year seedling develops better than direct seed planted or cutting plants. The young plant requires water system during first sweltering climate. Sanctuary is alluring in beginning phases in nursery and 
furthermore in the wake of transplanting. The general development pace of plant is moderate.

\section{BOTANICAL DESCRIPTION}

Haritaki plant is a medium-sized deciduous tree with variable appearance, up to $25 \mathrm{~m}$ tall, with a generally short barrel shaped bole of 5-10 m length, at bosom tallness is 60$80 \mathrm{~cm}$ in breadth, crown adjusted, with broadening branches, bark dim earthy colored, for the most part longitudinally split with woody scales, branchlets corroded villous or glabrescent [4]. Leaves of haritaki are exchange or inverse, ovate or elliptic-obovate, thin-coriaceous, $7-12 \mathrm{~cm}$ long and 4-6.5 cm wide, inhumane to subacute at summit, adjusted at base, pubescent underneath, petiole up to $2 \mathrm{~cm}$ since quite a while ago, given 2 organs at the base of the leaf cutting edge [7, 8].Haritaki plant blossoms in axillary $5-7 \mathrm{~cm}$ long spikes, straightforward or at some point spread, around $4 \mathrm{~mm}$ over, yellowish-white and disagreeably scented, calyx 5-lobed, stamens 10, corolla missing, ovary sub-par, exserted, 1-celled [11].Natural Fruit an obovoid or oval ellipsoid drupe, 2.5-5 $\mathrm{cm}$ long, faintly 5-rakish fit as a fiddle, yellow to orangeearthy colored when ready, glabrous [12].
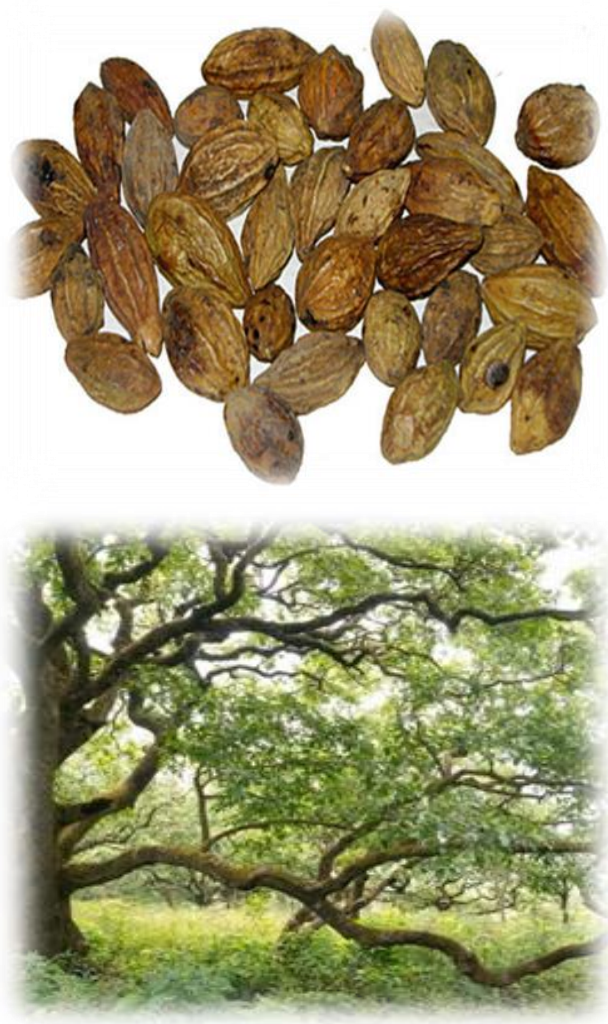
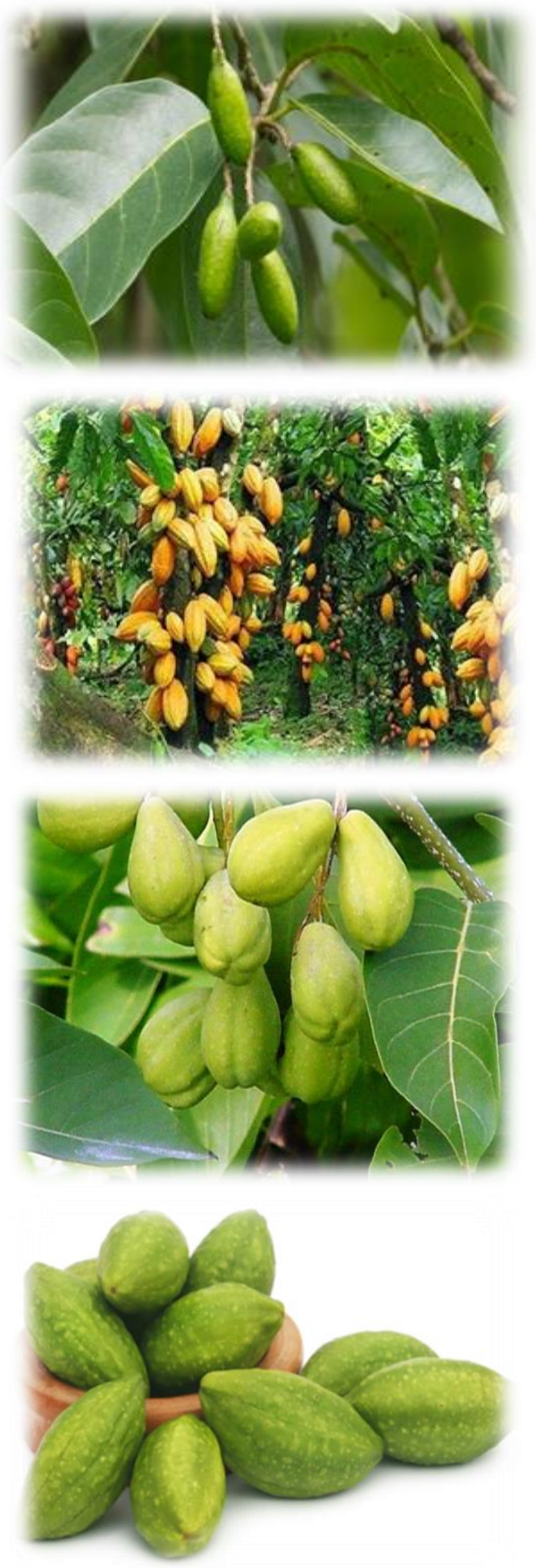

Fig 1:- Haritaki fruit, leaf and tree [1-25]. 
5. CLASSIFICATION OF HARITAKI $[1,3,5,6,8,9,10,11$, 16].

\section{A. AS INDICATED BY THE SIZE OF THE FRUIT [8]-}

(i)Survari harade - This kind of harade are thick, overwhelming and huge around 2 inches in length, yellowish-earthy colored, when cut it contains yellowish or darkish earthy colored, mash and stone and the mash is astringent in taste

(ii) Rangari harade - This sort are less wrinkled, littler and less wrinkled than the above assortment; long about an inch; the epidermis is yellow; when cut it presents a yellow dried mash and a stone. The mash is less astringent in taste than that of survari harade.

(iii) Bala harade -This sort are littler than the over two assortments. Profound earthy colored or dark in shading; exceptionally wrinkled, dull or earthy colored epidermis and their mash is dim and homogenous; there is no stone.

(iv) Java harade - This are the littlest of all and different characters are like Bala harade.

B. CLASSIFICATION AS PER SHAPE $[1,3,6,8,9,10,11$, 16]-

(i) Vijaya - This sort having alabu shape utilized in all infections, and living space in Vindahya Mountains.

(ii) Rohini - It is Round fit as a fiddle, utilized in vrana, natural surroundings in zansi and different conditions of India.

(iii) Pootana - It have little size, mesocarp is less, seed is greater, remotely utilized, habitate Sind.

(iv) Amirtha- Mesocarp of this sort is often utilized for shodhanakarma habituate

(v) Abhya- This kind of Fruit having five ribbed utilized in eye infections, habitate champaranya, Himalaya.

(vi) Jeevantee - This sort organic product is brilliant yellow in shading, utilized in all infections, habitate Himalaya.

(vii) Chetaki - This kind of Fruit having three ribs, utilized as laxative.

C. CLASSIFICATION AS INDICATED BY THE DEVELOPMENT OF FRUIT [8]-

(i) Halileh - Zira. At the point when the size is that like a cumin seed.

(ii) Halileh - Javi. At the point when the size is that like a scarcely corn.

(iii)Halileh - Zangi. At the point when the size resembles a raisin.

(iv)Halileh - Chini. At the point when organic product is greenish yellow in shading and to some degree hard.

(v) Halileh - Asfer. At the point when it is practically full grown organic product.

(vi)Halileh - Kabul. It is completely developed natural product.

\section{ACCORDING TO VARIOUS PHASES OF DEVELOPMENT OF NATURAL PRODUCTS [8]-}

Chattopadhyay and Bhattacharyya grouped the Haritaki into three kinds as per various phases of development of natural products-

(a) Small Myrobalan- the juvenile fruit.

(b) Yellow Myrobalan- after improvement of seed, this is the experienced phase of the natural product.

(c) Large Myrobalan- the completely developed organic product.

\section{MACROSCOPIC STUDIES}

Shading Fruit are yellowish-earthy colored in shading, shape-ovoid, size-for the most part 20-35 mm long, 13-25 $\mathrm{mm}$ wide, wrinkled and ribbed longitudinally [12]. Pericarp is sinewy, $34 \mathrm{~mm}$ thick, non-follower to the seed. Astringent in taste $[12,15]$.

\section{MICROSCOPIC STUDIES}

\section{a. Transverse section-}

The transverse area of pericarp shows epicarp which comprising of one layer of comprises of 2-3 layers of collenchymas, trailed by a wide zone of parenchyma wherein filaments and sclereidu in gathering of vascular groups are dissipated $[12,15]$. The filaments have peg like out development and basic pitted dividers. Sclereids are having different sizes and shapes however for the most part extended [12]. Epidermal surface shows uncover polygonal cells, consistently thick walled a few of them isolated into two by slim septa [12]. The starch grains are basic, estimating 2-7 $\mu \mathrm{m}$ in distance across, oval or adjusted fit as a fiddle, found in bounty in all cells of mesocarp [15].

\section{b. Powder microscopy-}

The powdered medication is caramel in shading and shows a couple of strands, vessels with straightforward pits and gatherings of sclereids under magnifying lens and Vessels with basic pits and gatherings of sclereids $[12,15]$.

\section{PHYTOCHEMICALS}

Fruits contain about $30 \%$ of an astringent substance and astringency is because of Characteristic rule of chebulinic acid [9].Haritaki are a rich wellspring of Gallic acid dependent on auxiliary metabolites (20-36\%) [9].

The significant constituents of Haritaki are chebulagic acid, chebulic acid, chebulanic acid and Other compounds are tannic acid, Gallic acid ( 1.2\%), ethyl gallate, ellagic acid, chebulinic acid, chebulanin, corilagin, punicalagin, terflavin A, casuarinin, glucose, terchebulin, and 2,4chebulyl- $\beta$-D-glucose esterified with gallic acid to various degrees (eg., 1,6-O-galloyl- $\beta$-D-glucopyranose), Hydroxy anthraquinones glycosides $[4,7,8,9]$.

Haritaki fruit likewise contain tannic acid (20-40\%) gallic acid, resin etc. and anthraquinone nature which indicated purgative principle (IPC 155, USD 1529) $[4,7,9$, $15]$. 
Different kinds of compound recognized in the fruits are $[4,9]-$

a. Shikimic acid and related mixes like quinic acid, dihydroshikimic acid, 5- dihydroshikimic acid.

b. Sugars like arabinose, fructose and sucrose.

c. Triterpenoids like chebupentol, termioic acid, Arjunolic acid, arjungenin.

d. Steroids like $\beta$ - sitosterol, daucosterol.

It is likewise answered to have 18 amini acids and a little amount of phosphoric acid, succinic acid, syringic acid and quinic acids. Twelve basic unsaturated fats were separated from Haritaki of which, linoleic acid, oleic acid, palmitic acid were main constituents $[4,9,15,11]$.

The tannin content of haritaki mainly depends on its geographical distribution [5]. Haritaki comprise 33\% of the all-out phytoconstituents are hydrolysable tannins and which may differ from 20-half and that are liable for pharmacological activity in human body $[5,9,15,11]$.<smiles>O=C(O)c1cc(O)c(O)c(O)c1</smiles>

(a) Gallic acid.<smiles>O=C(O)CC1c2c(cc(O)c(O)c2O)C(=O)OC1C(=O)O</smiles>

(d) Chebulic acid.

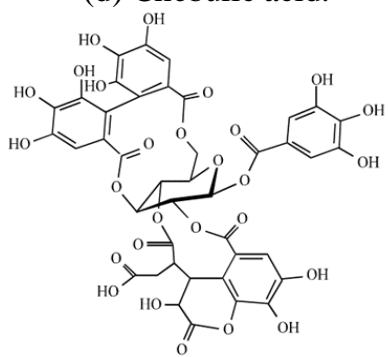

(f)Chebulagic acid.<smiles>COc1cc(C(=O)O)cc(O)c1O</smiles>

(b) Syringic acid.

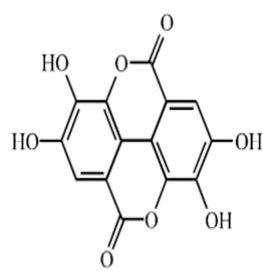

(c) Ellagic acid.

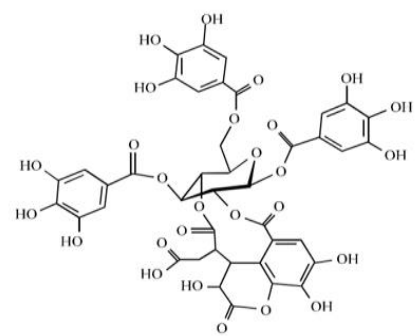

(e)Chebulinic acid.

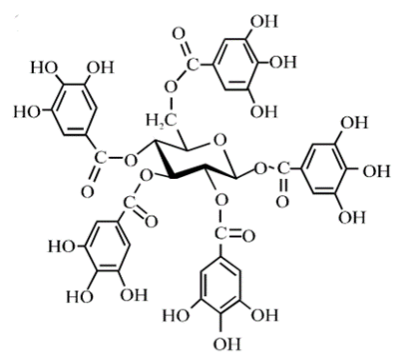

(g) Penta-o-galloyl- $\beta$-Dglucose.

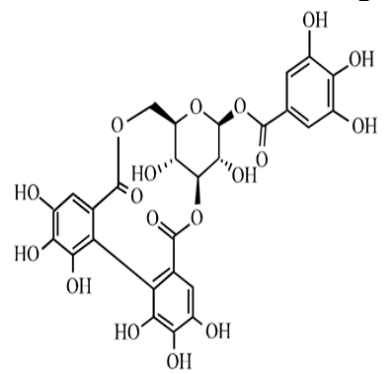

(h)Corialgin.

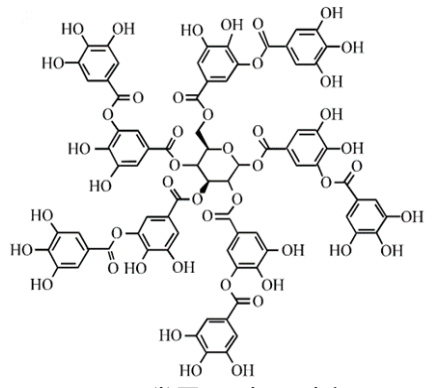

(i)Tannic acid.

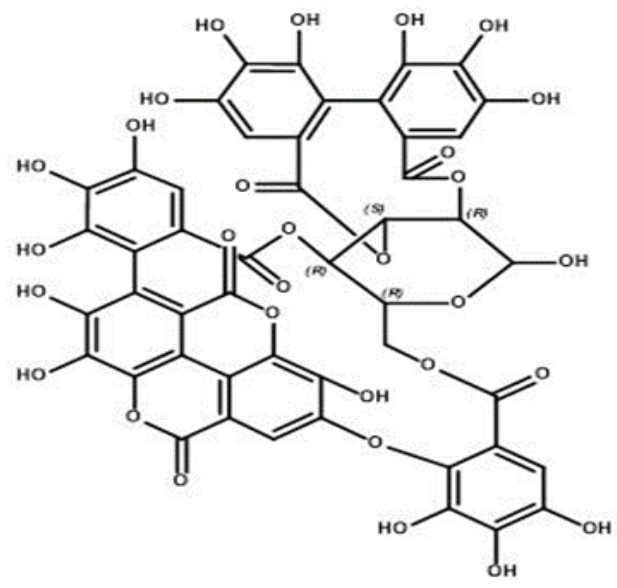

(j)Terchebulin

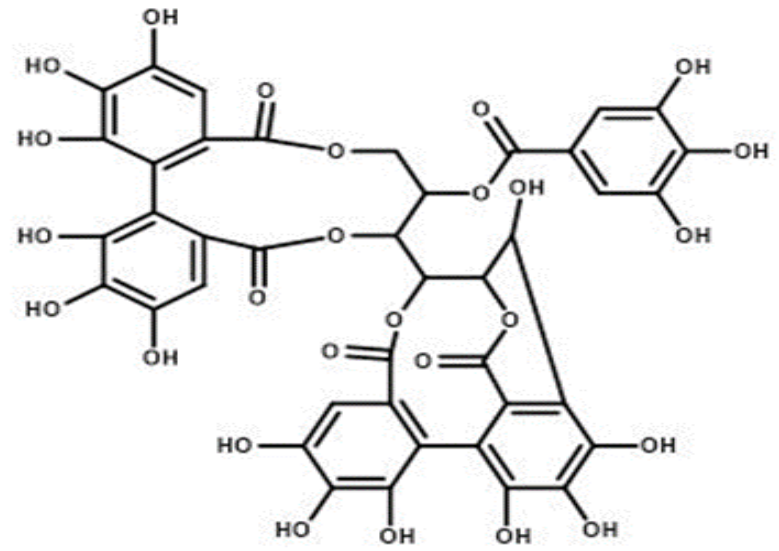

(k) Casuarinin.<smiles>CCOC(=O)c1cc(O)c(O)c(O)c1</smiles>

(1)Methyl gallate.

(m)Ethyl gallate.

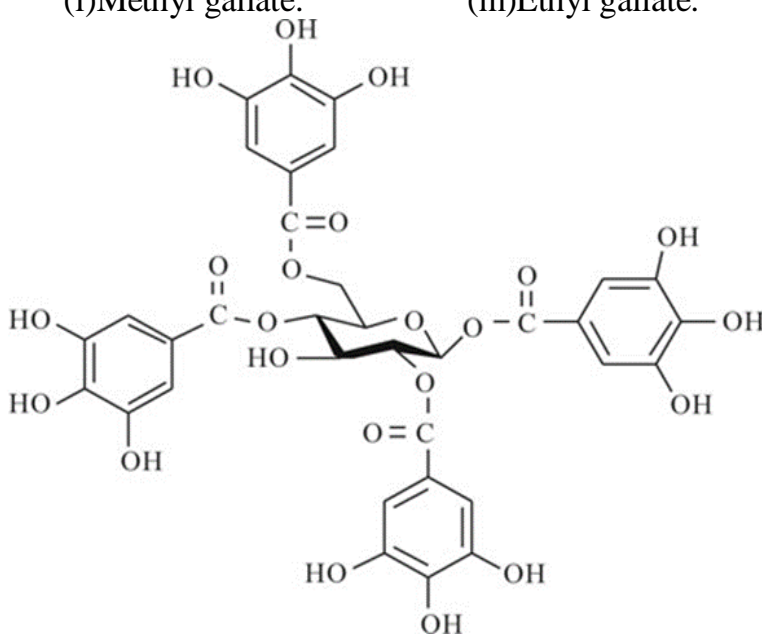

(n)Tetra-O-galloyl- $\beta$-D-glucose.

Fig.-2 (a-n): Structure of the some major components or phytochemicals isolated from Haritaki are shown in the fig. $[4,5,7,8,9]$. 


\section{* DIFFERENT MEDICINAL ACTIVITIES}

Now a day, pharmaceutical companies are being interested towards the herbal medicine, and much of researches are being to publish the pharmacological actions of varied phyto-chemicals found in plants. As we've previously discussed that Haritaki is one of the foremost common used drug in Ayurveda and ethno medicine. Different modern researches have proved its various pharmacological actions also. Pharmacological actions of Haritaki as per modern researches are-

\section{> 1.WOUND HEALING ACTIVITY}

The impacts of topical administration of an alcohol(ethanolic) concentrate of the leaves and fruits of Haritaki within the sort of an ointment with two concentrations (5\% and $10 \% \mathrm{w} / \mathrm{w}$ ointment of bark extract in simple ointment base) saw as powerful with improved paces of constriction and diminished time of epithelialization in albino rats contrasted with controls [17]. Biochemical investigations of Haritaki distributed a major increment in complete protein, DNA and collagen substance inside the granulation tissues of rewarded wounds [1]. The extensible quality of tissues from separate rewarded entry point wounds expanded by about $40 \%$. Also, Tannins removed from juvenile products of Haritaki hindered Staphylococcus aureus and Klebsiella pneumonia in vitro and advances cutaneous injury recuperating in rodents because of a solid antibacterial and angiogenic action of the concentrate [18].

\section{ANTIVIRAL ACTIVITY}

Haritaki fruits go about as incorporate inhibitors of four immunodeficiency infection type 1 (HIV-1), Gallic corrosive (I) and three galloy glucoses (II-IV) [4]). Their galloyl moiety assumes a primary job for restraint against the 3'preparing of HIV-1 integrase of the mixes has additionally retroviral polymerase inhibitory movement [4].Its offers security to epithelium cells against Influenza - A virus, supporting its conventional use for helping in recuperation from intense respiratory contaminations. Themethanol and fluid concentrates indicated an immense inhibitory action with on human immunodeficiency infection 1 polymerase [19].Kurokawa et al. (1995) has additionally shown its remedial movement against Herpes simplex infection (HSV) both in vitro and in vivo tests [20]. Yukawa et al. (1996) a group of Japanese analysts to assessed the impacts of Terminalia chebula's on human cytomagalovirus (CMV) and they found that Terminalia chebula was compelling in repressing the replication of human cytomagalovirus in vitro and in an AIDS model with immunosuppressed mice and ended that it will be advantageous for the avoidance of CMV infections and immonocompronised patients [4]. It's additionally advantageous in explicitly transmitted ailments (STD) and AIDS [21].

\section{ANTIFUNGAL ACTIVITY}

A fluid concentrate of Terminalia chebula showed antifungal action against sort of dermatophytes and yeasts [22]. It is viably works against the pathogenic yeast Candida albicans and dermatophytes Epidermophyton, Floccosum, Microsporum gypseum and Trichophyton rubrum [4]. Inhibitory impact of three dermatophytes (Trichophyton spp.) and three yeasts (Candida spp.) appeared by a fluid concentrate of nerves and it's additionally been well documente [5]. In vitro anticandidal movement of methanol concentrate of Terminalia chebula was seen against clotrimazole which safe Candida albicans [23]. Antifungal movement displayed by the Terminalia chebula Seed separate against Trichophyton glabrata [22].

\section{ANTIBACTERIAL ACTLVITY}

Terminalia chebula displayed antibacterial movement against very both Gram-positive and Gram-negative human pathogenic microorganisms [5]. The Terminalia chebula extricate shows expansive range activitiy. The ethanol separate (alcoholic concentrate) indicated most extreme restraint against Salmonella epidermidis followed by Bacillus subtilis utilized at a level of $1 \mathrm{mg}$ for each circle [4]. The watery and methanolic concentrate of the leaf of Terminalia chebula at a level of $10 \mathrm{mg} / \mathrm{ml}$ are well viable in creating antibacterial exercises against gram-negative microbes especially to the specialists causing gastroenteritis [24]). Terminalia chebula showed antibacterial movement against assortment of bacterial species [5]. Butanol part of natural product remove ellagic corrosive and oxalic corrosive had solid antibacterial action against intestinal microorganisms, Clostridium perfingens and Escherichia coli. Malekzadeh et al. (2001) found that it's successful in restraining the urease action of Helicobactor pylori, and pervasive bacterium appended with the occasion of gastritis, ulcers and stomach tumors [25].From Terminalia chebula ethanolic separate disconnected gallic corrosive and ethyl ester of gallic corrosive that hes the antimicrobial action against methicillin-safe Staphylococcus aureus [26].Ripe seeds of likewise displayed solid antibacterial movement against Staphylococcus aureus and The fluid concentrate of unequivocally repressed the development of Streptococcus mutans, salivary microbes [13].It has additionally development inhibitory activity against typhoid bacillus (Rani and Khullar, 2004) and intestinal microscopic organisms [11]. The concentrates of Terminalia ends up being a productive enemy of bacterial specialist by framing the inhibitory zone against Pseudomonas aeruginosa, P. fluorescens, Bacillus bronchiseptica, Staphylococcus Salmonella epidermidis. B. cereus, B. pumilis, Shigella boydii and Escherichia coli [4].

\section{ANTI-OXIDANT ACTIVITY}

Concentrates of Terminalia chebula tried that three are new likely wellsprings of normal cell reinforcements for food and nutraceutical items [27].The methanol concentrate of Terminalia chebula had the most extreme absolute triterpenoid content and displayed great cancer prevention agent movement in the HRP-luminol- $\mathrm{H}_{2} \mathrm{O}_{2}$ measure [4]. The water remove seemed to have the best complete phenolic and tannin content and demonstrated great cancer prevention agent exercises in both CUSO4-Phen-Ve-H2O2, and luminol- $\mathrm{H}_{2} \mathrm{O}_{2}$ examines [4].The $95 \%$ ethanol separate showed great cancer prevention agent movement in the pyrogallol-luminol measure Thus, the three concentrates present different degrees of ROS rummaging effectiveness due to contrasts between the components of the four ROS chemiluminescence frameworks [9].Aqueous concentrate of 
normal herb, Terminalia chebula opposed xanthine/xanthine oxidase action and it is additionally a brilliant forager of DPPH radicals [14].It is ended that the watery concentrate of Terminalia chebula goes about as a solid and groundbreaking cell reinforcement and since it can powerfully shield cell organelles from the radiation-initiated harm, it might be considered as a plausible radioprotector [28].Protective impacts of a fluid concentrate of Terminalia chebula natural product on the tert-butyl hydroperoxide (tBHP)- actuated oxidative injury which was seen in refined rodent essential hepatocytes and rodent liver and It has more grounded cell reinforcement action than alpha-tocopherol [4].HPLC investigation with diode cluster discovery and revealed the nearness of hydroxybenzoic corrosive subordinates, hydroxycinnamic corrosive subsidiaries, flavonol aglycones and their glycosides, as primary phenolic mixes [29].On contrast and the common watery extraction strategy the extraction proficiency was most noteworthy for microwave treatment followed by ultrasonication (Thomas et al., 2012) [4].The study distributed a $17.6 \%$ expansion inside the yield of phenolics and a $14 \%$ increment inside the tannin substance of the microwave extricates and the cell reinforcement action increment $20.6 \%$ in the microwave remove was likewise gotten [13]. The sonication extricates mean an ascent of 0.6, 5 and $9.69 \%$ inside the yield of phenolics, tannins and cancer prevention agent action, individually [4].

\section{- 6.HEPATOPROTECTIVE ACTIVITY}

Organic products are large wellspring of chebulic acid, tannin and elagic acid that have critical job of an astringent and hepatoprotective [9]. It was viewed as significant since the crude occasions to manage the liver physiology in haemorrhoidal conditions and now it is very notable that gateway hypertension can be a significant etiological factor in the improvement of hemorrhoids $[1,9]$. The $95 \%$ ethanolic concentrate of Terminalia chebula natural product meant hepatoprotective movement against hostile to tuberculosis (antiTB) medicate incited poisonousness which could be ascribed to its unmistakable enemy of oxidative and film balancing out exercises [9, 14]. Tasduq SS tried that ethanolic concentrate of Terminalia chebula was found to forestall the hepatotoxiocity which brought about by the organization of rifampicin, isoniazid and pyrazinamide (mix) in sub-constant model (12 weeks) [9, 20]. A blend of chebulic acid (CA) and its minor isomer, neochebulic acid with a proportion of 2:1 secluded from ethanolic concentrate of Terminalia chebula organic products demonstrated solid hepatoprotective action and in a home grown definition (HP1) displayed hepatoprotective action against carbon tetrachloride prompted harmfulness in rodent hepatocytes $[14,20]$.

\section{> 7. ANTIMUTAGENIC ACTIVITY $[1,2,6,7,8,9,10,11,17]$}

The tannin parts and Gallic acid acquired from the dried organic product mash of Terminalia chebula were assessed for their antimutagenic potential. They all were profoundly fundamentally dynamic against S9-subordinate mutagen 2AF.However, chebula tannins were incompletely viable against NPD mutagen yet not in any way compelling against mutagen 4 NQNO. The impact compares with the idea of the divisions; and the monomeric gallic corrosive adequacy was the least compelling. A fluid concentrate of Terminalia chebula decreased NPD just as 2-AF incited revertant altogether in strains of Salmonella typhimurium. The test likewise noticed that autoclaving of the fluid concentrate decreases the irrelevant inhibitory impact. The water concentrate of $\mathrm{T}$. chebula organic products mash restrained the immediate acting mutagens sodium azide and 4-nitro-ophenylendiamine in the strains TA100, TA1535, TA97a, TA98 of Salmonella typhi murium and S9-subordinate mutagen 2-aminofluoren in TA97, TA98 and TA100 strains and numerous different strains. The chloroform and acetone concentrates of Triphala demonstrated restraint of mutagenicity actuated by direct and $\mathrm{S} 9$-subordinate mutagens in TA98 and TA100 analyzer strains of Salmonella typhimurium. In the VITOTOX Test for location of DNA harms in prokaryotic and eukaryotic cells natural product removes from Terminalia chebula were not genotoxic. This outcome is reliable with another Ames Test. In any case, in the COMET test indicated that expanded DNA harms with a substance over 500 ppm.

\section{ANTICANCER ACTIVITY}

In human malignant cell lines a $70 \%$ methanolic concentrate of Terminalia chebula organic products mash indicated diminished the cell suitability, restrained the cell expansion and incited the cell demise in a portion subordinate way $[9,13]$. In lower concentrations insignificant apoptosis was initiated however at higher portion fixations corruption was the significant instrument of the cell demise. The accompanying IC50 qualities could be uncovered: Chebulinic acid: $53.2+/-0.16 \mu \mathrm{M}$, tannic acid 59.0+/-0.19 $\mu \mathrm{M}$, ellagic acid $78.5+/-0.24 \mu \mathrm{M}$, individually $[9,14]$.

Cytotoxic movement with the tannin portion of Terminalia chebula organic products and the tannins of Terminalia chebula, particularly chebulanin were protected in Japan for its anti-cancer movement [6]. Reddy DB et al. assessed concentrate of Terminalia chebula natural product with ethanol restrained cell expansion and presented cell demise in a portion subordinate way in a few harmful cell lines including human (MCF-7) and mouse (S115) bosom malignancy cell line, human osteosarcoma cell line (HOS-1), human prostate disease cell (PC-3) and a non-tumorigenic deified human prostate cell line (PNT1A) [3]. Chebulagic acid, a COX-LOX double inhibitor extricated from the products of Terminalia chebula Retz. Instigates apoptosis in COLO205 cell line $[13,14]$.

\section{CYTOPROTECTIVE ACTIVITY $[4,5,7,9,11,13,14$, 20]}

Ethanolic concentrate of Terminalia chebula natural product show critical cytoprotective impact against UV Binitiated oxidative harm. These perceptions were doled out to the inhibitory impact of the concentrate of Terminalia chebula on the age subordinate shortening of the telomere length as appeared by the Southern Blots of the Terminal Restriction Fragments (TRFs) of DNA that was separated from sub-culture entries. The ethanolic concentrate of $\mathrm{T}$. chebula natural product displayed a striking cytoprotective impact on the HEK-N/F cells and oxidative pressure and 
inhibitory impact on cell maturing of its organic products have additionally been very much recorded.Have performed on the various concentrations of gallic acid and chebulagic acid, were confined from the concentrate of the home grown medication (myrobalan, the product of $\mathrm{T}$. chebula) as dynamic head that hindered the cytotoxic T-lymphocyteintervened cytotoxicity. Granule exocytosis in response to anti-CD3 incitement was additionally hindered by gallic and chebulagic acid at the identical concentrations. It showed the advancement of duodenal ulcers and seemed to apply a cytoprotective impact on the gastric mucosa in vivo.

\section{CARDIOPROTECTIVE ACTIVITY}

Entire organic product mash of Terminalia chebula is professed to be helpful in the treatment of heart ailments and Cardioprotective impact of ethanolic concentrate of haritaki natural products $(500 \mathrm{mg} / \mathrm{kg}$ body weight $)$ was explored and found to enhance the impact of isoproterenol on lipid peroxide arrangement and held the exercises of the symptomatic marker compounds in isoproterenol which actuated myocardial harm in rodents [11, 20]. It was accounted for that the concentrate of Terminalia chebula pretreatment had a cardioprotective impact in the exploratory rodents due to the lysosomal layer adjustment forestalling myocardial rot and hindrance of changes in the ultrastructure of heart mitochondrial and work [7].It was accounted for that in segregated frog heart model pericarp of Terminalia chebula additionally show cardioprotective action and various concentrates from the dried mash without parts have been applied on separated frog hearts, and furthermore have been performed for each organic product extricate ten-to fifteen trials, the outcomes are the normal of them $[4,9,13$, 20].

\section{> 11.RADIO-PROTECTIVE,CHEMO-PROTECTIVE AND CHEM-MODULATORY ACTIVITY}

Evaluations in an exploratory investigation, the fluid concentrate of the product of Terminalia chebula $50 \mu \mathrm{g}$ had the option to neutralize 1, 1diphenyl-2-picrylhydrazyl, a steady free radical by $92.9 \%$ and shielded the plasmid DNA pBR322 for a fact the gamma radiation-instigated harm [30].Concentrate of Terminalia chebula diminishes illumination impacts in mice, human lymphocytes while experiencing the gamma radiation-in vitro [30].

Terminalia Chebula extract in dose of $80 \mathrm{mg} / \mathrm{kg}$ body weight preceding entire body illumination of mice brought about decrease of peroxidation of film lipids in the liver and lessening in radiation-initiated harm to DNA [5]. Treatment of mice with watery concentrate of Triphala in various dosages progressively for five days before light deferred the beginning of mortality and decreased the side effects of radiation affliction contrasted with controls [14] Chemopreventive impact on nickel chloride, appeared by Terminalia chebula which in male Wistar rodents instigated renal oxidative pressure, cell multiplication and harmfulness reaction [5]. For malignant growth anticipation Terminalia chebula concentrate could be utilized as remedial operator since it blocked or stifled the activity related with compound carcinogenesis [11].

\section{HYPOLIPIDEMIC AND HYPOCHOLESTROLEMIC ACTIVITY}

Concentrate of Terminalia chebula administration indicated hypolipidaemic movement against tentatively incited atherosclerosis and hypocholesterolemic action against cholesterol-initiated hypercholesterolemia and atherosclerosis [9, 14].In hyperlipidaemic model prompted atherogenic diet, the rodents accepting treatment with Terminalia chebula that indicated significan bringing down in all out protein, all out cholesterol, triglycerides, and furthermore ascending of high thickness lipoprotein cholesterol that demonstrating significant hypolipidemic action [4]. Terminalia chebula at 1.05 and $2.10 \mathrm{mg} \mathrm{kg}$ concentrations are show a fantastic lipid-bringing down operator and hypolipidaemic impacts need to establish in Triphala formulation, when it tentatively actuated on the hypercholesteremic rodents [4, 14]. The ethanolic concentrate and ethyl acetic acid derivation parts of products of Terminalia chebula were found to have critical hypolipidemic movement and the ethyl acetic acid derivation portion of immature fruits of Terminalia chebula was most dynamic concentrate which had the option to carry high serum lipids to typical level $[4,11,7]$. In a test study including that cholesterolaemia and cholesterol content in rabbit's aorta and liver was decline by Terminalia chebula altogether. No expanded discharge of cholesterol is found during concentrate thus the activity may be intervened through enzymic debasement of cholesterol in the liver or somewhere else [9].

\section{$>$ 13.ANTIDIABETIC AND RETINOPROTECTIVE ACTIVITY}

The counter diabetic property of therapeutically dynamic plants and its relationship with their cancer prevention agent potential have for some time been built up [4]. The methanolic concentrate of Terminalia chebula, Emblica officinalis, Terminalia bellerica, and their mix named Triphala was found to restrain lipoid peroxide arrangement and rummage hydroxyl radical and superoxide radicals inside the diabetic rodents affirming their antidiabetic potential [4]. Moreover, the renoprotective impacts and antidiabetic impacts of the chloroform concentrate of Terminalia chebula Retz Seeds in streptozotocin-initiated diabetic rodents was recognized [4]. The chloroform concentrate of Terminalia chebula seeds made portion subordinate decrease in blood glucose level in blood of diabetic rodents contrasted and standard medication glibenclamide in both short and long term study [9]. The chloroform concentrate of T. Chebula displayed imperative renoprotective action and furthermore more adequately repressed the occurrence of diabetic nephropathy [7]. Lee et al. (2011) detailed that methanolic concentrate of Terminalia chebula containing $2.7 \%$ chebulic acid demonstrated prophylactic impacts against the development of advanced glycation end products (AGEs) and in epithelium cell pathology [1].Once the impacts of Terminalia chebula concentrate on AGE arrangement and on protein crossing connecting by glycation with D-threose and focal point crystallines were inspected, concentrate of Terminalia chebula indicated abusive movement in a portion subordinate way and furthermore the grouping of $1000 \mu \mathrm{g}$ mL-offered an 
action like that of $5 \mathrm{mM}$ aminoguanidine as a positive control [4]. The brooding of Human Umbilical Vein Epithelium cells (HUVEC) with $100 \mu \mathrm{g} \mathrm{ml-}$ of advanced glycation end products (AGES) caused a significant increment in THP-1 monocytic cell grip, however this bond was decreased by the treatment of concentrate of Terminalia chebula[13].This indicated concentrate of Terminalia chebula is an expected specialist for mitigating diabetic entanglements [3].

\section{NEUROPROTECTIVE ACTIVITY}

The water and methanol concentrates of Terminalia chebula show neuroprotective exercises against $\mathrm{H}_{2} \mathrm{O}_{2}$, prompted harmfulness toward $\mathrm{PCI}_{2}$ cells and are likely contender for the treatment of $\mathrm{H}_{2} \mathrm{O}_{2}$-initiated neurodegenerative malady [9]. The compelling neuroprotective action of the water separate is result of its 'OH and $\mathrm{H}_{2} \mathrm{O}_{2}$, searching exercises, its most prominent extraction yield and its complete phenolic and tarnin content [4].

\section{ANTISPASMODIC ACTIVIT}

Terminalia chebula indicated 'anti-spasmodic' properties by the decrease of irregular circulatory strain just as intestinal fits in different vivo and in vitro investigations [5] This guarantee its conventional utility for spastic colon and other intestinal issue[7]. Antispasmodic Activity Crude concentrate of Terminalia bellerica organic product caused the relaxation of unconstrained constrictions in the separated rabbit smooth muscle jejunum at a grouping of $0.1-3.0$ $\mathrm{mg} / \mathrm{mL}$ and guinea pig ileum readiness it delivered an equal rightward move of acetylcholine bends [11]. Castor oilprompted looseness of the bowels and carbachol-intervened bronchoconstriction, in both case concentrate of Terminalia chebula indicated insurance movement [13]. The authors expressed that the combination of anticholinergic and $\mathrm{Ca} 2+$ effects showed by extract of Terminalia chebula which may explain its folkloristic use [14].

\section{> 16. ANTI-ULCEROGENIC ACTIVITY}

The animals pretreated with doses of 200 and $500 \mathrm{mg}$ kg-1, Terminalia chebula hydroalcoholic concentrate demonstrated fundamental decrease in injury file, absolute influenced space and extent of sore as contrasted and control bunch against the impact of aspirin, ethanol and cold limitation stress-instigated ulcer models[14]. Similarly extricates expanded mucus production against the impact anti-inflamatory medicine and in ethanol-incited ulcer models. Terminalia chebula separate indicated antisecretory movement at dosages of 200 and $500 \mathrm{mg} / \mathrm{kg}$ in pylorus ligated model which cause a rebate inside the stomach related juice volume, free causticity, complete acridity and fundamentally expanded gastric $\mathrm{pH}$ [14]. This action along these lines loans pharmacological assurance to the proposed utilization of the plant as a characteristic cure inside the treatment or the executives of ulcer [14].

\section{GASTROINTESTINAL MOTILITY IMPROVING ACTIVITY}

Terminalia chebula natural product has been appeared to expand gastric purging time [11]. Antiulcerogenic movement of Terminalia chebula appeared to be offset with a defensive impact on the gastrointestinal mucosa, with the improvement inside the secretory status of Brunner's organ required inside the assurance against peptic ulcer [5]. Inside the Indian medication framework Terminalia chebula might be an ordinarily utilized specialist for improving gastrointestinal motility [13]. With Charles Foster rodents gastric discharging was estimated during this analysis Terminalia chebula $(100 \mathrm{mg} / \mathrm{kg} /$ day $)$ infused in Rats that expanded their gastric exhausting with 86.57+/ - 6.65 $\%(\mathrm{p}<0.01)$ contrasted and typical rodents $(51.6+/-7.79 \%)$. From this investigation Terminalia chebula can fill in as an option in contrast to prokinetic drugs accessible today [13].

\section{> 18. PURGATIVE AND LAXATIVE PROPERTY}

Purgative activity of an oil division from Terminalia chebula has been accounted [5]. The stools increments by Terminalia chebula and has got property of emptying the bowel totally showed in a momentary clinical preliminaries did on patients with straightforward clogging [14].Laxative Anthraquinone subordinates show laxative action by animating the mucous layer lead to increment in discharge of bodily fluid i.e invigorating peristalsis [9]. Gonstipation and rectal spasm are remove by Terminalia chebula fruits extract and show safe and effective as a gentle laxative [9]. The pericarp of the natural product has been seen as a glycoside Anthraquione that might be like sennoside that causes the laxative principle [9].

\section{ANTIPLASMODIAL ACTIVITY}

Bhagvan et al (2011) was considered, antiplasmodial movement of Terminalia chebula concentrate against Plasmodium falciparum [6]. Terminalia chebula, water separate represses the take-up of $[3 \mathrm{H}]$ hypoxanthine into the Plasmodium falciparum K1 multidrug-safe strain and in vivo because of this Terminalia chebula, water remove indicated antiplasmodial movement in vitro [3]. The Terminalia chebula seeds acetone extricate essentially indicated antiplasmodial movement against Plasmodium falciparum [3, 6].

\section{ANTI-AMOEBIC AND ANTI-PROTOZOAL ACTIVITY}

The medication plan of Terminalia chebula was explored for anti-amoebic impact in test caecal amoebiasis in rodents and result demonstrated corrective pace of $89 \%$ at $500 \mathrm{mg} / \mathrm{kg}$ body weight due fluctuating degrees of hindrance of catalyst exercises like RNase, DNase, aldolase, acid phosphatase, soluble phosphatase, $\alpha$-amylase and protease in axenically refined amoebae [19]. 


\section{ANTI-ALLERGIC ACTIVITY}

As an element of a polyherbal formulation (Aller-7), Terminalia chebula demonstrated strong anti-allergic action in vitro condition [19]. Anti-histamine and anti-spasmodic in guinea pig ileum impact showed by Terminalia chebula Hydro-ethanol extricate. Fluid concentrate of Terminalia chebula organic product when Orally administrated in rodents, it fundamentally put down histamine discharge from rodent peritoneal mast cells 117 and furthermore altogether expanded creation of tumor necrosis factor (TNF) by antidinitrophenyl $\operatorname{IgE}[11,19]$.

\section{> 22. MOLLUSCICIDAL ACTIVIY [4]}

Upadhyay and Singh (2011a) detailed that potential source of biomolluscicides is Terminalia chebula fruit against Lymnaea acuminata. This test report indicated, tannin is available as a functioning segment in Terminalia chebula natural product that was described by High Performance Liquid Chromatography. Further it had been assessed that in vivo and in vitro introduction of tannin fundamentally restrained the acetylcholinesterase (AChE), acid phosphatase (ACP) and alkaline phosphatase (ALP) action inside the nerve tissue of Lymnaea acuminata. These snails are the host of Fasciola hepatica Fasciola gigantica which causes $94 \%$ fascioliasis inside the wild ox populace of northern India. The dynamic segment of Terminalia chebula organic product that shows molluscicidal movement, that is solvent in carbon tetrachloride, chloroform, ether, acetone and ethanol. The poisonousness of ethanolic concentrate of Terminalia chebula natural product powder is above different concentrates which shows that the molluscicidal part present is more dissolvable in ethanol than other natural solvents.

\section{IMMUNOMODULATORY EFFECT}

The active phytoconstituents of Terminalia chebula extract named gallic acid and chebulagic acid demonstrated immunosuppressive impacts, on cytotoxic $\mathrm{T}$ lymphocyte (CTL) intervened cytotoxicity and also blocked [4]. In addition, the killing action of CD8+ CTL clone at IC, hindered by gallic acid and chebulagic acid, at estimations of 30 and $50 \mathrm{M}$, separately [4, 19]. Moreover, gallic acid and chebulagic acid was also blocked the granular exocytosis in light of hostile to CD3 incitement that further confirm its immunosuppressive impact [4, 19].

\section{EFFECT ON NF-KB}

Different genes associated with cell endurance, angiogenesis, proliferation, inflammation, intrusion and metastasis, among different procedures, those genes communicated by movement of atomic factor kappa-light chain-enhancer of initiated $B$ cells $(N F-\kappa B)$ [1]. When concentrate of Terminalia chebula presented, it hindered NF$\kappa \mathrm{B}$ action and unequivocally smothered $\mathrm{I} \kappa \mathrm{B} \alpha$ phosphorylation and ensured against $\mathrm{I} \kappa \mathrm{B} \alpha$ debasement in Jurkat-NF-кB-RE-bla cells [1]. The Terminalia chebula separate additionally causes downregulated certain $\mathrm{NF}-\kappa \mathrm{B}$ directed genes, including IL-8 and MCP-1, in JurkatNF-кBRE-bla cells. Terminalia chebula phytochemical gallic acid was showing its capacity to restrain NF- $\kappa B$ action in JurkatNF- $\kappa$ B-RE-bla cells [1].

\section{ANTI-DERMATOPHYTIC EFFECT}

Three dermatophytes (Trichophyton spp.) and three yeasts (Candida spp.) repressed by a watery concentrate of Terminalia chebula [1, 3]. A fluid concentrate of Terminalia chebula indicated higher inhibitory impacts than ethanol separates in light of essence of tannins in watery concentrate of Terminalia chebula. The tannins are the phytochemical that indicated antidermatophytic impacts of Terminalia chebula $[1,3,15,31]$.

\section{EFFECT ON BRONCHIAL ASTHAMA}

A clinical study in Ayurveda has been reported evaluating two important Ayurvedic formulations on bronchial asthama (Tamak shvasa) named viz. Shvasaharaleha and Vasaharitakiavaleha [1]. In this study proved that the Terminalia chebula containing Vasa Haritaki avaleha provided better relief in bronchial asthama than Shvasahara Leha [1].

\section{ACETYLCHOLINE INHIBITION ACTIVITY [1]}

In the suggestive treatment of Alzheimer's illness Acetylcholinesterase inhibitors have been broadly utilized. Terminalia chebula isolated phytochemical named 1,2,3,4,6penta-O-galloyl- $\beta$-D-glucose showed significant butyrylcholinesterase and acetylcholinesterase inhibitory effects comparable with Tacrine. . At the point when tried in examination with different herbs Terminalia bellirica, and Emblica officinalis and Triphala with Terminalia chebula, the watery concentrate of Terminalia chebula demonstrated most noteworthy viability to restrain acetylcholinesterase.

\section{ANTI- HELMINTHES ACTIVITY}

Acetone, ethyl acetic acid derivation and methanol concentrates of dried leaves and seeds of Terminalia chebula indicated ovicidal and larvicidal exercises and those analyzed in vitro condition, on Haemonchus contortus dependent on tests of egg bring forth and larval improvement at 50, 25, $12.5,6.25$ and $3.13 \mathrm{mg} / \mathrm{ml}[3,7]$. The concentrates of leaves and seeds of Terminalia chebula at $50 \mathrm{mg} / \mathrm{ml}$ indicated total hindrance [3].

\section{ANTI-INFLAMMATORY AND ANTI-ARTHRITIC ACTIVITY}

Watery concentrate of dried product of Haritaki by repressing inducible nitric oxide amalgamation demonstrated mitigating movement [5]. Chebulagic acid removed from juvenile seeds of haritaki smothered essentially the beginning and movement of collagen incited joint inflammation in mice [11]. Haritaki showed a portion subordinate mitigating impact in a polyherbal formulation (Aller-7) against Freund's adjuvant incited joint inflammation in rodents [3, 14].

\section{ADAPTOGENIC AND ANTIANAPHYLACTIC ACTIVITIES $[5,11,19]$}

For checking adaptogenic potential in animal, among the six Ayurvedic herbs the Haritaki herbs was one that injected in animal. Additionally, this animal contemplates show that when concentrate of Haritaki was controlled after enlistment of anaphylaxis, demonstrating its strong antianaphylactic activity when the serum histamine levels were decreased. Haritaki's water soluble fraction produced a 
noteworthy expanding impact on hostile to dinitrophenyl IgE-instigated tumor putrefaction factor-alpha creation from rodent peritoneal pole cells demonstrating its high antianaphylactic activity.

\section{ANTI-UROLITHIATIC ACTIVITY}

Anil. T. Pawar et al. in their examination, the fluid concentrate of the product of Terminalia chebula in wistar albino rats diminished the significant levels of oxalate and phosphate in pee just as kidney tissue homogenate [9].The concentrate supplementation likewise forestalled the height of serum levels that is available in Blood urea nitrogen, Creatinie and Uric acid [9].

\section{> 32. ANTI-SPERMATOGENIC ACTIVITY}

Gupta et al. have performed on the oral organization (300 mg/kg body weight for 28 days) of the bark of Terminalia chebula extricated in acetone, methanol, and half ethanol and in watery solvents caused histological adjustments in rewarded mice testicles seminiferous tubules [7].

\section{> 33. ANTI-hsv-2[9]}

Ajay Kesharwani et al. In their investigation, half ethanolic extricate from the products of Terminalia chebula or mixes chebulagic and chebulinic acid, their impact on the reasonability of Vero cells chose by MTT test [9]. The concentrate of Terminalia chebula uncovered 409.71 \pm 47.70 $\mu \mathrm{g} / \mathrm{ml} \mathrm{CC50}$ esteem. When the chebulagic and chebulinic acids tried up to $200 \mu \mathrm{g} / \mathrm{ml}$ it showed $>95 \%$ cell reasonability. The concentrate from Terminalia chebula $(\mathrm{IC} 50=0.01 \pm 0.0002 \mu \mathrm{g} / \mathrm{ml})$, chebulagic $(\mathrm{IC} 50=1.41 \pm 0.51$ $\mu \mathrm{g} / \mathrm{ml}$ ) and chebulinic acids (IC50 $=0.06 \pm 0.002 \mu \mathrm{g} / \mathrm{ml}$ ) indicated hostile to viral action in vitro against HSV2 and demonstrated portion subordinate potential. Oyuntsetseg $\mathrm{N}$ et al. assessed and recorded that the watery concentrate acquired from the seeds of Terminalia chebula demonstrated anti-viral action on influenza A (H3N8) virus [9].

\section{> 34. MELANIN INHIBITORY EFFECT}

The concentrate of Terminalia chebula as protected powerful de pigmenting operator have incredible potential. Melanin inhibitory impact above $90 \%$ at 100 ppm appeared by methanolic concentrate of Terminalia chebula (Jin Yin-Z et al.) [9]. Khanna A.K et al. demonstrated that ceaseless taking care of ester dissolvable part of the alcoholic concentrate of Terminalia chebula stem for 30 days to typical rodents expanded the amount of HDL-C and brought down the amount of LDL-C [9].

\section{> 35. ANTICARIES AGENTI1, 5, 9, 11, 14]}

Anticaries action exarted by fluid concentrate of Terminalia chebula firmly restrained the development, sucrose actuated adherence and glucan instigated the aggregate sum of Streptococcus mutans in the spit tests up to $3 \mathrm{~h}$ after.10\% arrangement of the concentrate of Terminalia chebula that hindered the salivary bacterial check and glycolysis of salivary microscopic organisms for upto $90 \mathrm{~min}$ post flushing. Separated extact of Terminalia chebula indicated preventive activity on dental caries.

\section{PROKINETIC EFFECT[4]}

Legitimate gastric exhausting has been identified with the correct remedial impacts appeared by the medication treatment and therefore, it's basic that the gastric purging procedure stays appropriate. The oral administration of Terminalia chebula on gastric discharging has been researched to confirm its intense prokinetic impact [4]. Metoclopramide essentially expanded the gastric exhausting (76.3312.37\%; $\mathrm{p}<0.01)$ and atropine restrained the motility percent gastric purging $(7.26+19.76 \%$; $\mathrm{p}<0.01)$. Terminalia chebula extricate was found to broaden the percent gastric exhausting (86.57_6.65\%; $\mathrm{p}<0.01)$ which demonstrated that Terminalia chebula concentrate may work a valuable option to prokinetic drugs accessible [4].

\section{IMMUNOSUPPRESSIVE EFFECTS [13]}

Gallic and Chebulagic acid, secluded from concentrate of fruit pulp of Terminalia chebula hindered the executing movement of CD8 and CTL clones at IC50 estimations of 30 and $50 \mu \mathrm{M}$, separately. Granule exocytose in light of hostile to $\mathrm{CD} 3$ incitement was additionally hindered by the two substances at the equal portion depended fixations [13].Chebulagic acid separated from concentrate of juvenile seeds of Terminalia chebula might be a strong silencer of the $\mathrm{T}$ cell movement. In DBA/ $1 \mathrm{~J}$ mice model of joint inflammation subcutaneous vaccination with ox-like sort II collagen on days 0 and 21 .

Chebulagic corrosive was managed i.p for 3 weeks, either as a treatment $(20 \mathrm{mg} / \mathrm{kg})$ after malady beginning or as prophylaxis (10 or $20 \mathrm{mg} / \mathrm{kg}$ ) before ailment beginning. In both the prophylactic and either in the restorative model, all clinical score, similar to serum levels of aggregate and anticollagen IgG and levels of interleukin-10 and interleukin6 were altogether decreased [13].Serum levels of the changing development factor beta were especially increased.when infused chebulagic acid in mice the quantity of the granulocytes was diminished, however the extent of CD4+, CD25+ and T cells was more prominent in the knee joints. Creators communicated that chebulagic corrosive altogether stifled the beginning and movement the malady in mice [13].

\section{CONCLUSION}

The plant of Haritaki has the potential of treating various kind of diseases and has got many medicinal activity like anti-oxidant, wound healing, anti-microbial, anti-fungal, anti-diabetes, anti-ulcer, anti-dermatophytic, Cardioprotective, Hypolipidemic and Hypocholesterolemic and many more yet to be discovered or experimented upon.The presence of many medicinally active phytochemical such as Gallic acid, Syringic acid, Ellagic acid, Chebulic acid, Chebulinic acid, Chebulagic acid, Penta-o-galloyl- $\beta$-D-glucose and other potent chemicals makes it a very potent plant yet to be used by the medicinal industry. It is need to explore this plant very thoroughly and researchers are exploring the therapeutic potential of this plant.The review of the literature thus concludes that the plant is a very useful medicinal plant. 


\section{ACKNOWLEDGMENT}

I am thankful to our principal Dr Amandeep sir, our subject teacher and my Mentor Mr. Bhupendra Tamta sir and also my institute Dev bhoomi institute of pharmacy and research for being supportive and providing me with all the guidance during the conduction the review.

\section{REFERENCES}

[1]. D. M. K. a. A. B. Patil, "PHARMACOLOGICAL AND THERAPEUTIC POTENTIAL OF TERMINALIA CHEBULA RETZIUS - A CRITICAL REVIEW," World Journal of Pharmceutical AND Medical Research , pp. 226-234, 2016.

[2]. S. N. Priya Patil1, "HARITAKI: PRAYOGBHEDEN PHALBHEDNAH," INTERNATIONAL AYURVEDIC MEDICAL JOURNAL, vol. 6, no. 8, pp. 1812-1815, 2018.

[3]. D. s. k. Dr.Shalu sharma, "A Critical Review of Pharmacological Action of Haritaki(Terminalia chebula Retz.) In classical texts," Journal of Ayurveda and Integrated Medical Sciences, pp. 258-269, 2019.

[4]. P. A. a. D. s. Aparna upadhyay, "A REVIEW ON THE PHARMACOLOGICAL ASPECTS OF TERMINALIA CHEBULA," INTERNATION JOURNAL OF PHARMACOLOGY, pp. 289-298, 2014.

[5]. N. K. Ran Vijai K. S. Maurya1*, "Haritaki (Terminalia chebula Retz.): A Magic Bullet for Various Remedies," International Journal of Pharmaceutical \& Biological Archives , pp. 1 - 8, 2016.

[6]. S. S. a. M. L. Monika Agrawal1, "Haritaki (Terminalia chebula Retz.), A Boon of Nature: A Review," Int J Ayu Pharm Chem , pp. 46-53, 2018.

[7]. S. Z. H. Hilal Akhtar1, "A Descriptive Review on Traditional Herbal DrugTerminalia Chebula," Journal of Advanced Research in BioChemistry and Pharmacology, vol. 2, no. 1, pp. 21-28, 6 june 2019.

[8]. R. a. G.Thilagavathi, "Terminalia Chebula - Review on Pharmacological and Biochemical Studies," International Journal of PharmTech Research , vol. 6, no. 1, pp. 97-116, 2014 .

[9]. T. M. W. V. M. K. H. M. K. Nalini Sofia H*1, "Phyto Pharmacology and Ethnomedical Approach of Terminalia chebula (Kadukkaai): A Review," Scholars Academic Journal of Pharmacy (SAJP) , pp. 446-453, 2017.

[10]. S. Thirumoorthyswamy, "Pleiotrophic Evaluation of Haritaki," American Journal of Phytomedicine and Clinical Therapeutics , pp. 033-044, 2014.

[11]. S. K. B. R. R. C. Anwesa Bag, "The development of Terminalia chebula Retz. (Combretaceae) in clinical research," Asian Pacific Journal of Tropical Biomedicine, pp. 244-252, 2013.

[12]. k. s. r. b. s. s. m. Yadav Babita, "A PERSPECTIVE STUDY OF HARITAKI," INTERNATIONAL JOURNAL OF RESEARCH IN AYURVEDA AND PHARMACY, pp. 1466-1470, 2011.
[13]. M. E. a. C. R. Arbind K1, "Ethnopharmacological Review of Terminalia chebula," Bioequivalence \& Bioavailability International Journal, vol. 3, no. 1, pp. 1-8, 4 January 2019.

[14]. B. S. A. N. Thrigulla Saketh Ram1*, "Review Article PRAGMATIC USAGE OF HARITAKI (TERMINALIA CHEBULA RETZ): AN AYURVEDIC PERSPECTIVE VISÀ-VIS CURRENT PRACTICE," International Journal of Ayurveda and Pharma Research , pp. 72-82, 2013.

[15]. A. M. P. B. R. S. S. K. V. G. A Gupta1*, "Phytochemistry and pharmacological activities of Haritaki - A review," Journal of Pharmacy Research, pp. 417-424, 2010.

[16]. P. K. K. D. A. K. S. D. R. C. M. D. P. S. a. D. M. P. Dr. Deepak Verma1*, "AN ANALYSIS OF TRIPHALA POWDER WITH TTHE IMPORTANCE OF HARITAKI(TERMINALIA CHEBULA LINN.) SPECIES: ANCIENT MIRACLE FORMULA," World Journal of Pharmaceutical Research , pp. 452-458, 2017.

[17]. G. Choudhary, "Wound healing activity of the ethanolic extract of Terminalia chebula Retz.," International Journal of Pharma and Bio Sciences, vol. 2, no. 1, pp. 48-52, 2011.

[18]. Y. D. H. Z. S. W. Z. Z. B. Y. S. H. H. Y. Kun Li 1, "Tannin Extracts From Immature Fruits of Terminalia Chebula Fructus Retz. Promote Cutaneous Wound Healing in Rats," BMC Complement Altern Med, vol. 10, no. 8, pp. 11-86, 2011.

[19]. *. S. A. P. Pansare T. A., "The Vayasthapan Karma (Age Sustaining Action) Of Haritaki (Terminalia Chebula Retz.)- A Review," International Journal of Ayurvedic and Herbal Medicine, pp. 2484-2500, 2017.

[20]. A.l.o.o.panelMasahikoKurokawaaKazuhikoNagasakaa TatsujiHirabayashiaShinichiUyamaaHidekiSatoaTakas hiKageyamaaShigetoshiKadotabHaruoOhyamacToyoh aruHozumicTsuneoNambabKimiyasuShiraki,

"Efficacy of traditional herbal medicines in combination with acyclovir against herpes simplex virus type 1 infection in vitro and in vivo," Antiviral Research, vol. 27, no. 1-2, pp. 19-37, 1995.

[21]. S. B. R.R. Chattopadhyay, "PHCOG REV Terminalia chebula.: Plant Review," Pharmacognosy Reviews , vol. 1, no. 1, pp. 151-156, 2007.

[22]. I. R. T. K. D. B K Dutta 1, "Antifungal Activity of Indian Plant Extracts," Mycoses, vol. 41, no. 11-12, pp. 535-536., 1998.

[23]. G. H. S. Bonjar, "Inhibition of Clotrimazole-resistant Candida Albicans by Plants Used in Iranian Folkloric Medicine," Fitoterapia, vol. 74, no. 1, pp. 74-76, 2004.

[24]. A. A. A.-A. S. M. N. M.Bakric, "Antimicrobial activity of some plant extracts against bacterial strains causing food poisoning diseases," Saudi Journal of Biological Sciences, vol. 25, no. 2, pp. Volume 25, Issue 2, February 2018, Pages 361-366, 2018.

[25]. E. H. S. N. L. M. C. R. Malckzadeh F, " Antibacterial activity of black myrobalan (Terminalia chebula Retz.) against Helicobactor pyroli.," Int J Antimicrob Agent , vol. 18, no. 1, pp. 85- 88, 2001. 
[26]. O. H. S. K. O. T. K. M. S. H. e. a. Sato Y, "Extraction and purification of effective antimicrobial constituents of Terminalia chebula Retz. against methicillin resistant Staphylococcus aureus," Bull Pharm Bull, vol. 20, no. 4, pp. 401-404, 1997.

[27]. L. C. Chang CL, " Development of antioxidant activity and pattern recognition of Terminalia chebula Retzius extracts and its fermented products," HungKuang J , vol. 61, no. 4, pp. 115-129., 2010.

[28]. B. K. K. S. M. B. Y. J. K. Y. S. Y. Y. S. M. N. Na MK, "Cytoprotective effect on oxidative stress and inhibitory effect on cellular Terminalia chebula fruit.," Phytotherapy research, vol. 18, no. 9, p. 737-741, 2004

[29]. H. P. H. K. P. Saleem M, "Inhibition of cancer cell growth by crude extract and phenolics of Terminalia chebula fruits.," J Ethnopharmacol, vol. 87, no. 3, pp. 327-3236, 2002.

[30]. N. C. Gandhi NM, "Radiation protection by Terminalia chebula some mechanistic aspects.," Mol Cell Biochem, vol. 277, no. 1-2, pp. 41-48, 2005.

[31]. F.-T. AssieJokar, "Potential therapeutic applications for Terminalia chebula in Iranian traditionalmedicine," Journal of Traditional Chinese Medicine, pp. 250-251, 2016. 